Library Hi Tech, Vol. 17, No. 1, 1999, pp.55-62.

ISSN: $0737-8831$

DOI: 10 1108/07378839910267217

http://www.emeraldinsight.com/Insight/viewPDF.jsp?contentType=Article\&Filename=html/Output/Published/Emer aldFullTextArticle/Pdf/2380170107.pdf

http://www.emeraldinsight.com/Insight/viewContainer.do?containerType=JOURNAL\&containerId=11298

URL journal

OMCB Press

\title{
E-reference: incorporating electronic publications into reference
}

\author{
Courtney L. Young is Diversity Intern Librarian, Ohio State \\ University Libraries, Columbus, Ohio, USA.
}

\author{
Karen R. Diaz is Web Librarian, at the Ohio State University \\ Libraries, Columbus, Ohio, USA.
}

\begin{abstract}
The traditional work of reference librarians has been greatly impacted by access to electronic publications on the World Wide Web. Reference librarians are also using the Web to create electronic publications for in-library users and Web surfers. By creating HTML documents that provide access to Web and other electronic resources, reference service is extended beyond the physical library and designated reference desk hours, opening the building for 24-hour access.

As our definition of traditional reference service expands and evolves, so do the resources we use to provide that service. Electronic publications -resources not in a printed format which are accessible through the use of a computer with a modem or CD-ROM drive - deliver information to library users as a complementary alternative to printed reference collections. While most people would define electronic publications as electronic databases, full-text journal articles, and catalogs, a new resource is now possible. Reference librarians themselves are participating in the electronic publication trade by creating Web pages and finding aids to assist both themselves and their users to locate information electronically on the World Wide Web. The same Web medium that poses a new challenge for librarians offers major new tools to give us the power to control our own situation.
\end{abstract}

\section{The traditional environment}

\section{Decisions, decisions}

The World Wide Web has created for reference librarians a new powerful tool that is actually many tools in one. Information that was once only available to large libraries with budgets to afford large collections is suddenly now available to any library with Internet connections. Owing to community, academic, private, and government funding, that now means virtually every public and academic library. Questions that once might have taken days to answer, or might not have been at all answerable in certain environments, now can often be managed within minutes. While largely an asset, this new tool brings new challenges to reference librarians.

Reference librarians are faced with new choices in the realm of collection development. Nancy Reger states "We not only need to keep abreast of new reference content available on databases and the Web, but we are also trying to do some evaluative comparisons between our print and virtual reference collections" (Reger, 1998). Publishers of quality and important reference works increasingly are making these available electronically. Librarians are sometimes 
faced with choosing one format or another. Electronic versions are certainly more accessible to a wider audience. Users may be able to access electronic versions from home, when they have never before had the opportunity to take printreference materials out of the library. If designed well, search capabilities for the resource should be enhanced to provide greater access at another level.

Sometimes the electronic aspect of the resource might actually be a deterrent to access. When a user wants to walk away with a copy of a concise table of statistics, it might be quicker and easier for the librarian to pull out a well-known print resource, hand it over to the user, and point the user in the right direction to a copy machine than it would be to:

- wait with the user to gain access to a machine;

- lead the user through the steps needed to get into the right resource;

- search within that source; and

- explain how to print a copy (for which the user has to pay).

There are also times when a user needs to understand the arrangement and purpose of an entire resource, in order to understand the terminology and types of information the user can expect to cull. The user might be happier browsing through pages rather than reading unconnected help screens and search pages. Determining reliability of the source of information is one more step the user might have to make when accessing the greater Web for an answer. "When we look at the expansion of the reference process caused by electronic resources, there are additional new steps in the process for us which include: determining the quality of answers from the Web; and instructing users in the use of the tools" (Reger 1998).

Reference librarians make both collection development and immediate reference decisions by examining whether they would expect to find an answer in a for-cost resource versus a freely accessible site on the greater Web. Some authors have attempted to categorize what types of questions are most appropriate for the Web (Dickstein et al., 1997). While such guidelines for current events, business, government information, popular culture, sports scores, medical conditions, Internet information, and travel and tourism are helpful, they cannot account for every site or exception to the selection rule. Reference librarians must not be comfortable only with their own collections, but also have a good sense of how and when to try searches out on the Web. Much of this has to be learned by individual trial and error.

Chuck Koutnik corroborates some of the statements made above concerning the types of questions most answerable on the Web. He conducted a study of specific reference questions and documented whether or not answers could be found on the Web (Koutnik, 1997). While determining the categories of the most answerable types of questions, the author also studied how much time it took to get to the answer on the Web versus in print. While such a time and motion study is quite interesting, it is largely impossible to make sweeping statements about speed without considering the full range of a user's needs that go beyond retrieving specific facts. It may be quicker to use a terminal to read a quick fact over the phone to someone, but if document delivery is part of the reference problem, other factors may intervene.

\section{Harvesting search engines}

Just as a combined knowledge of a library's reference collection, plus mastery of the search capabilities and structure of the library catalog, give the reference librarian the power to 
deliver answers through the library collection, so too does a combined knowledge of basic and important resources on the Web, plus mastery of major search engines, give a reference librarian the power to deliver answers through the Web. In the early days of many search engines, librarians and users bemoaned the problem of wading through ridiculously large result sets with thousands of hits to find the one site that truly delivered the information desired. Increasingly there is no need for this. By learning advanced techniques such as phrase versus Boolean searching, the use of metatags, combining phrases with domains, and being specific, users can expect more manageable results. The weighted results many search engines provide, while not perfect, tend to make useful information appear first.

Distinguishing between search engines (such as AltaVista) and search directories (such as Yahoo!) can also assist both the librarian and the user to get the right type of information more quickly. When facts are needed, a search engine might be more appropriate. When more general information and context are needed, directories might offer a more logical approach. Directories can lead to sites containing facts which, while not necessarily indexed by a general search engine, are searchable within that site. Directories can also help to cull the types of resources being searched, because their levels often limit which selections are included. Bigger is not always better. There are directories that only collect and index scholarly Web sites.

While search engines are certainly becoming sharper and more powerful tools for taming the Web, the sheer numbers now available add a new element for confusion. As of this writing there are 17 major search engines with over 100 regional, specialty and other search engines available for searching all or parts of the Web (Sullivan, 1998). If reference librarians learn how to use all these tools aggressively, they will still be able to save the time of the reader, even in this domain outside of the library walls.

Librarians are more in tune than general users with what has been termed "the dark side of the Web": those electronically-based materials that are not accessible through search engines. They may be delivered via the Web and provide access via their own search engines, but the riches of their information are inaccessible to the mega search engines.

\section{Technostress resolved and exacerbated}

Literature searches on electronic publication can turn up articles as recent as three years old that focus mostly on electronic journals and mention terminology which is essentially nonexistent today; i.e. gopher, veronica, archie...even ftp. Reference librarians at the start of the decade worried about providing access to gopher and ftp'able articles. At issue were such realities as having equipment available in a public place with Internet access, developing technical expertise for downloading, and evaluating and keeping abreast of what materials were available to users. While many of these issues have been resolved through the unifying interface of the Web, search engines, and seamless techniques for ftp'ing, some remain, and several new problems have arisen.

Libraries continue to stretch their budgets to provide enough terminals for users who want to accomplish so much more than online catalog searching. As libraries increase the number of databases leased or accessed, they increase local demand for convenient access to terminals. In addition they face a growing challenge in limiting what gets done on these workstations, since they access not only library materials, but a whole Web-based world of games, chat rooms, e-mail sites, pornography and e-commerce. When libraries create policies limiting acceptable use, reference librarians are put on the spot. They are expected to be vigilant, 
to be able to make judgments about what is unacceptable behavior, and to confront users whom they deem to be acting against policy.

Limitations on access rights are often confusing to library users. It is not clear to many why they can get to some resources listed on a library Web site from their homes with no problem, and get blocked from others. Distinctions between a paid subscription service and what is just another Web site may seem pointless while on the seamless interfaces within library doors or on library network nodes, but matter greatly from a user's home computer. While the technical staff have to bear the load of coming up with solutions to these access problems, it is the reference staff who must explain to the public why access is not available, or why it is achieved in a different manner from home.

While some of the technological aspects of accessing and downloading information have become easier through the Web, plugins, helper applications, and smarter off-line software have made life in a reference environment more difficult. For example, different vendors provide different solutions for delivering full text for printing and downloading. Some accomplish this through the browser, many use PDF (portable document format), and some use their own proprietary software. Additionally, databases and other services to which libraries subscribe update the technology running their services at varying rates. This means unevenness in what browser requirements exist for the entire panoply of services. While efficient library automation support services may set up library workstations to handle all the issues that arise within their doors, reference staff work with increasing numbers of remote users who have their own workstations, software, and technical expertise. If the reference staff have not been involved in configuring library workstations, they may be totally unaware of where the pitfalls for remote users might exist.

This is why, although many technological issues are resolved, reference librarians are experiencing new levels and new types of technostress at the desk. It is quite likely that in another three years time, the issues outlined here will be moot, but it is unlikely that there will be no technological issues for reference staff to juggle and attempt to master.

\section{User expectations/expertise}

Electronic publications and the sometimes misguided hype of their availability have created heightened expectations from users approaching reference staff for assistance. There is often the sense that by pressing a few buttons on a computer, information tailored to the need of the individual will appear. In a twist to the former opening line, "Do you have any books on...?", librarians are sometimes approached with the line, "Can you find something on the computer about...?" With technology changing as rapidly as it is, it is sometimes heralded in the media when in fact it only exists in experimental form. Sometimes a particular technology never even makes it to production, or remains too expensive for libraries.

In an opposite vein, there is also a running paranoia among many in libraries that reference librarians will become extinct because users will become more independent and will no longer need to come in to libraries. With reference tools online, access from home will be common and people will learn to do what they need themselves. While it seems as though that potential exists, it is nearly impossible to draw the conclusion that it will come to pass. The burgeoning of computers has not lessened society's dependence on paper to the extent that some claimed would happen, and while the death of the book has been envisioned, the number of books published each year has only increased, and not yet even begun to decrease. 
One constant is that the nature of an individual's information needs often changes. Library users wear many roles in society as workers, parents, patients, hobbyists, etc. Librarians have always served a role in assisting users who are experts in one field to find information in another. In the keynote address at the conference on "Reference Service in a Digital Age", Bonnie Nardi noted that "we are in danger of moving toward a one size fits all world, which is often what we get from automation, instead of attention to the distinctiveness of particular local ecologies, which I think we should endeavor to preserve" (Nardi, 1998). In preserving these local ecologies, the role of the reference librarian remains the same, regardless of whether the sources are electronic or print.

Electronic publications have certainly affected how users find librarians. With library Web pages available for anyone to find listing names and e-mail addresses of librarians, it is much simpler to query a person than to try and figure out what language to use to query a machine. It is also still simpler for a novice or lost user to identify what individuals are appropriate (or close to appropriate) than to identify what machine is appropriate. At least one can hope to get an intelligible response or referral from a person, especially from a reference librarian whose goal is to be helpful. Most machines still offer little assistance or explanation when they don't have a match for the query.

\section{Trends}

This librarian witnessed a change in user patterns at one busy academic library reference desk. In 1994-1995 when the Web quickly grew in size, popularity and accessibility, the traffic at the desk began to slow a bit. (This is documented in an unpublished and internal document showing 1997 reference desk transactions in the Information Services Department, Ohio State University Libraries.) While the reference desk remains a busy environment, it has become more manageable. Recent discussions on an internal mailing list in the same library have examined the fact that there has been a dramatic increase in the number of e-mail requests that individual librarians are receiving by having a presence on the Web. Some of the questions and users are not appropriate to the library's mission, but a human being is there to provide appropriate referral. Without research which investigates the true reasons for this shift, it seems logical to attribute this wave of behavior to an increased independence of users at the outset of Web popularity, tempered by a confusion and return to some degree of dependence of users on information professionals as the Web has grown more complex in nature.

What remains somewhat unsure is whether there will be future waves of independence and dependence, or whether the technology will slow to a point that all but the dullest user can gain some degree of mastery over the content and technical aspects of the Web.

The ability for libraries to become publishers themselves in this great new world has also created a new venue for service. Librarians' names and e-mail addresses are often available for the world to find, and digitized library collections have become available to a much wider audience than could ever find them when they were locked away in protective rooms.

Librarians in all units of libraries question their role in a society of increased digitization, artificial intelligence, and computing resources. While it is obvious that reference librarians need to evolve in terms of technical skill, content knowledge, and envisioning of appropriate and effective service mechanisms, it seems unlikely that a profession which survived in the relatively accessible print world will suddenly be unnecessary in a more complicated digital environment. Access is a funny notion. It not only encompasses bits, bytes, network connections and software, 
it also requires a constant dialog with users to understand their needs and abilities in order to deliver the right service and the right content at the right time. "Dialog with users" is the hallmark of reference librarianship. While the tools for accessing information are becoming more powerful and omnipresent, the ability to master all of them is not necessarily a simpler task. The service element of librarians has not disappeared and seems unlikely to in the near future.

\section{Using the WWW to fight back}

The role of electronic publishing in libraries has taken on a new meaning. Libraries themselves are playing a huge role in the creation of electronic documents, specifically on the Web. The Web has become a publishing tool of choice for libraries. Whether it be for basic library information such as hours and telephone numbers, or for databases and Web resources, using HTML (Hypertext Markup Language ) to create, acquire, and distribute information is a driving force in many libraries. Although this new technology has changed and expanded reference service, librarians bring to the Web many of the same standards and principles they use in building library collections and providing service.

HTML, along with programming languages such as Perl and JavaScript, is being used on library Web sites to launch users into online catalogs, CD-ROM and online databases, as well as bibliographies. HTML is now becoming a common library school course, soon to be a requirement along with cataloging and reference. With library school curricula moving towards making technology competency a requirement, and the invention of HTML editors to make even the novice look like an expert, Web publishing has become an essential part of many librarians' jobs. By publishing reference information on the Web, librarians are able to provide access to pertinent information both locally and globally without time constraints. Users from within the library, as well as those from home with a connection to the Inter-net, are able to access these documents.

Libraries actively use the World Wide Web to deliver reference information. The relationship between reference and electronic publications for libraries is becoming a win-win situation, since both the users of these resources and their creators become "virtual." How exactly are librarians doing this? By developing Web sites for use within their libraries and around the world.

The main challenge of doing reference on and for the Web is anticipating the question of the virtual user. While general collection development policies and subject libraries make it easier to select resources that will answer potential questions, Web surfers are bound to ask and seek the answer to any question. How then do you provide resources and information to these unknown questions?

Some libraries are attempting to answer the unknown by building Web sites that anticipate the needs of both their local users as well as those of any Web surfer from around the world. Among these sites are the Librarian's Index to the Internet (LII), Cyberstacks(sm), Virginia Commonwealth University's My Library project, and Penn State University's (PSU) Help Yourself: Tell Me Where To Look.

My Library and Help Yourself are academic library sites that allow users to design their searching to specifically what they are looking for. LII and Cyberstacks(sm) offer broader Web surfing, with Sunsite using a more topic or keyword approach, while Cyberstacks(sm) imposes the Library of Congress Classification System (LCCS) to categorize Web sites. Each of these sites demonstrates how librarians in many different ways are trying to collect and provide access 
to information on the World Wide Web.

\section{Tools for local users}

Virginia Commonwealth University's "My Library" project is a reference tool patterned after commercial sites such as "My Netscape" that allows the user to be more active in the selection of resources[1]. The site lets a user customize a Web page to have specific resources and information available every time he or she logs in. VCU recognizes that not all library users are the same or interested in all the information that a library Web site might present. The user gets to interact in many ways, choosing what types of information are displayed from the Web page.

Penn State University's approach to assisting its users with World Wide Web resources is Help Yourself: Tell Me Where To Look, which allows users to choose the format of material they are looking for, whether it be a book, journal article, newspaper article, or government publication, and then select from a list of 27 broad subject areas[2]. Submitting a search for books or journal articles on health sciences and education yields a Web page listing the PSU online catalog and online databases such as ERIC or Academic Universe. Each resource is accompanied by an annotation and an explanation of how to connect to it. This electronic resource does exactly what it says: allowing users to help get themselves started with their searches for information electronically. Often users come to a reference desk wanting a simple push to get them started with their research. By providing a tool that allows researchers to get started right away looking for information based on broad topics, reference librarians end up conducting interviews with these same users at later and more in-depth points in their research.

\section{Tools for virtual users}

Although many librarians who do reference are not catalogers, they do rely on cataloging to provide access to information and printed resources. Since many libraries maintain catalog records for materials in an electronic format, what about maintaining a large reference Web resource in the same way? This is the approach some librarians are taking to create access in their Web sites. Cyberstacks(sm), for example, is a large Web site that uses the Library of Congress Classification System (LCCS) to organize knowledge on the World Wide Web[3]. Selection criteria is based on the American Library Association's Reference Collection Development: A Manual. Cyberstacks (sm) considers[4]:

- authority of the source;

- information accuracy;

- clarity of presentation;

- uniqueness within the context of the total collection;

- timeliness;

- favorable reviews; and

- community needs.

Selected Web sites are cataloged and arranged according to LC call number, just as a user would find materials in a physical library building. Cyberstacks(sm) implementation is based on the belief that LCCS offers a more effective way to structure, organize, and describe Web and Internet resources[5]. It allows users or Web surfers to "browse the shelves" and find selected 
Web sites, just as they would select books in the stacks.

Online and card catalogs contain records for materials used in providing reference service. Most online catalogs and electronic databases allow searching by author, title, subject, or keyword. Librarians use these same elements in Web publishing. The Librarian's Index to the Internet (LII) collects resources on the Web and classifies them in a broad subject or keyword approach (Leita, 1998a). Many Web users will start with a directory such as Yahoo! or search engine such as AltaVista, and type in broad search terms that result in hundreds of thousands of hits. LII indexers attempt to provide users with more accurate and useful information, saving them time and frustration.

This is based on the same basic collection development principles that libraries use in selecting books, serials, and index databases. LII's selection criteria consist of content, authority, scope, and design (Leita, 1998b). These selector criteria are the norm for libraries building their collections. LII is indexed and selected by 70 librarians on the LII Indexing Team from libraries across California. Carole Leita administers this project, which was launched in 1990 and evolved from Leita's Gopher bookmark file. In 1993, this file was placed on the Berkeley Public Library Web site and was known as the Berkeley Public Library Index to the Internet. When Leita began working with Roy Tennant at the Digital Library SunSITE, enhancements were made which included a search engine, subject index terms, and a system that would allow many librarians to add information to the index.

LII presents the user with a list of broad subjects, some with subdivisions, to begin searching for information on the Web. The searchable, annotated subject directory consists of more than 4,100 Internet resources. LII is a great approach to reference on the Web for many reasons. It is updated often. There is a wide variety of topics that would be useful to researchers and information seekers to select from at the top level. Librarians select all these sites with different backgrounds at different types of institutions.

\section{WWW as an extension of tradition}

One key concept for reference librarians in the traditional environment is a sense of place. Information in library buildings is placed and found by visual and contextual clues. Classification schemes give librarians browsing ability, making it seem as though the librarian has the placement of each and every book memorized. Sections for atlases, groupings of encyclopedias, and well-placed index tables are all devices that librarians have used to get a handle on reference materials to make them easy for users as well as themselves to find. How many librarians have been shaken in their efficiency when mass book shifts take place! This is one element that has yet to be regained in the online environment. While hypertext is a powerful way of drilling quickly to an answer, it is also quite possible to find the information and have no sense of context about where that information exists or who provided it.

One attempt to establish a sense of place on the Web is the Internet Public Library (IPL)[6]. This site is an interesting hybrid of the traditional and the new electronic environments. Its name, design, mission and information dramatically resemble a physical library. The reference selection actually takes the user to a drawing that looks like a reference room in a public library. A librarian sits at a reference desk where one can ask questions. The reference shelves are arranged by broad subjects that the user can browse through. The opening screen offers "pamphlets" for frequently sought information in a visible and obvious place. It brings to the Web a place for users to go to find the kind of information they expect to find in a library, 
and to get the interactive service they expect from a library. One reality of this virtual existence is that the interactivity is asynchronous. Users are warned that it might take a day or more to get answers to their questions. A list of frequently-asked reference questions lets users find more immediate answers on their own if they are willing to read through a simple, structured list.

What is most interesting about this site is its attempt to bring tradition to the Web. Interestingly, after over two years in existence, the staff of the IPL still consider it to be an experiment. Most of the reference librarians are volunteers. But the nature of its mission to serve traditional library-type needs and its willingness to provide that one-on-one service that is a hallmark of reference in libraries are important features of this site.

\section{Trends}

All of these sites are important reference sites on the Web. They begin to fill in the gaps found in search engines, directories, and the Web in general. Users increasingly demand and want to find electronic or Web-based information, and these sites are extensions of the superior service reference librarians and libraries provide. Librarians will increasingly be looked to to manage and interpret information on the Web. In many ways, the quickly expanding and evolving field of library and information science is incorporating this extension of reference work. As the information needs of users change, so must our involvement in it. Beyond simply providing access to the Internet, librarians must have a sense of what is out there.

The management of World Wide Web and Internet resources is an extension of the management of printed resources in libraries and very related to service librarians provide. However, these intangible resources are harder to acquire or even know about. The information is already there and librarians are just beginning to find ways to embrace its vast scope. The World Wide Web has the potential to be one of the largest collections of information possibly imaginable, and is a collection shared by all. Web publishing allows for libraries to participate in a worldwide consortium. Acquiring many of the materials is both easy and hard. There are no global standards as to how that acquisition and description should be done - whether by classification system or keyword. Yet this flexibility has allowed for new and effective ways for managing the information appropriate to certain types of libraries and their particular users. Librarians will continue to seek out ways to merge management and service to the information that exists on the Web, hopefully providing access to library users and Web surfers. Bringing them to these sites brings them to the library, though what we define as the library has drastically changed.

\section{Notes}

1 http://www.library.vcu.edu/mylibrary/test.html

2 http://www.lias.psu.edu/HelpingT1fullset.html

3 http://www.public.iastate.edu/ CYBERSTACKS/

4 http://www.public.iastate.edu/ CYBERSTACKS/signif.htm

5 http://www.public.iastate.edu/ CYBERSTACKS/LC_class.htm

6 http://www.ipl.org

\section{References}

Dickstein, R., Greenfield, L. and Rosen, J. (1997), "Using the world wide web and the reference desk," Computers in Libraries, September, pp. 61-5. 
Koutnik, C. (1997), "The world wide web is here: is the end of printed reference sources near?," $R Q$, Vol. 36 No.3, Spring, pp. 422-9.

Leita, C. (1998a), The Librarian's Index to the Internet [online]. Available http://sunsite.berkeley.edu/InternetIndex/

Leita, C. (1998b), Selection Criteria for Adding Resources to the LII [online]. Available: http://sunsite.berkeley.edu/ InternetIndex/pubcriteria.html

Nardi, B. (1998), "Information ecologies," Reference Services in a Digital Age: An LC Institute [Online], [cited 18 November 1998] Available from World Wide Web:http://lcWeb.loc.gov/rr/digiref/nardi.html

Reger, N. (1998), "Redefining reference services: transitioning the public library," Reference Service in a Digital Age: An LC Institute [Online], June, [cited 18 November 1998]. Available from World Wide Web:http://lcWeb.loc.gov/rr/digiref/whereger.html

Sullivan, D. (Ed.) (1998), Search Engine Watch [Online], [cited 23 November 1998]. Available from World Wide Web:http://searchenginewatch.com 